\title{
EVALUATION OF CLUSTER MANAGEMENT QUALITY BASED ON CONSUMER OPINION SENTIMENT ANALYSIS
}

\author{
Piotr MŁODZIANOWSKI*, Jose Aldo VALENCIA HERNANDEZ** \\ *Warsaw University of Technology, Faculty of Management \\ e-mail: piotr.mlodzianowski@pw.edu.pl \\ **Maynooth University, Centre for Entrepreneurship, Design and Innovation \\ e-mail: aldo.valencia@mu.ie
}

\begin{abstract}
This article discusses the issue of assessing the quality of cluster management by utilizing Internet customer feedback about companies that are members of clusters. Due to the growing number of Internet users, companies pay greater attention to the opinions published about them. Consumers are also increasingly willing to share their opinions and thoughts about the products they use. As a result, it has become possible to analyze the quality of services and products provided by an enterprise based on Internet opinions. In this article, we analyze the quality of cluster management as reflected in the European Cluster Excellence Initiative (ECEI) label, as measured by sentiment analysis of Internet opinions. The paper proposes a method for the identification and evaluation of Internet sources used in the opinion sentiment analysis. Sentiment analysis of Internet opinions of cluster and in-cluster business customers was performed, and the results were compared with the level of the ECEI label, which was awarded to the analyzed clusters. The conducted research showed convergences between formalized systems of management quality assessment and the level of opinions expressed on the Internet. The results testify that sentiment analysis can complement the evaluation of cluster management quality.
\end{abstract}

Keywords: management, management quality, sentiment analysis, cluster, opinion analysis.

JEL Classification: C45, L14, L15.

1

\section{Introduction}

In the age of digitization and a rapidly changing environment, companies and organizations depend on upto-date information about how consumers perceive their products and services. Continuous monitoring of consumer opinions and satisfaction levels leads, for example, to a better adjustment of product offerings to customer requirements and prevents image crises. Consumers also want to know what other users think about services or products before making a buying decision. This stems from a common practice of making decisions after reading opinions and confronting them with their expectations (Qazi, et al., 2017).

Until a few years ago, the most trusted source of opinions in the first place was family or friends (Perkins and Fenech, 2016). For businesses and organizations, the opposite was true. When they needed opinions regarding the products or services they offered, they conducted surveys, group interviews, and/or market research. It was a costly as well as time-consuming process and often the insight into why a product did not sell and consumers' dissatisfaction was received too late. Businesses and organizations increasingly rely on social media, online reviews, online forums, blogs, microblogs, Twitter, and online comments and articles for decision-making (Liu, 2011), including those made at higher levels of the organization (Jeyapriya, et al., 2015).

With the increase in the number of Internet users, increasing importance has been given to the information published on social networks. Consumers are willing to share their opinions and thoughts about products and services (Pozzi, et al., 2016), and the lack of an online presence of a business does not preclude sharing opinions about it online. This has made it possible to analyze the quality of services and products provided by a company based on online reviews. The increasing popularity of this phenomenon among researchers is also observed. Several studies have analyzed the sentiment of consumer opinions in relation to the evaluation of quality of service (QoS) (Albesta, et al., 2021), for example, in the hotel (Duan, et al., 
2013), restaurant (Nakayama, et al., 2019), and health-care industries (Abirami, et al., 2017). However, there is no research that could unequivocally establish a link between service quality evaluation and business management quality.

This issue concerns not only individual entrepreneurs, but also entire clusters of them, from suppliers to companies operating in related sectors, service units, or institutions related to them (Porter, 2001). Cluster management presents a challenge that many do not know how to meet; therefore, it is essential to assess cluster management quality. Initiatives to motivate better cluster management are being launched. Despite the existence of systems such as the European Cluster Assessment System, National Key Clusters, and Cluster Management Standards, there still remains a need for additional solutions that can rapidly and continuously assess cluster management quality.

The aforementioned consumer sentiment analysis may prove to be helpful in this respect.

The reasons discussed above prompted the authors of this paper to address this issue and pose a hypothesis that cluster management quality affects the level of customer business opinion sentiment regarding cluster members.

The hypothesis was tested by comparing the evaluation of cluster management quality, determined on the basis of sentiment analysis of online opinions of cluster and in-cluster business customers, with the level of cluster management quality measured by the European Cluster Excellence Initiative (ECEI) label. The topic is important because the ECEI evaluation system does not directly relate to the in-cluster businesses and the level of services they provide, and it is these businesses that can testify to the success of a cluster as well as the quality of its management.

The potential relationship between the evaluation of service quality and the quality of company/cluster management is important for cluster managers. It gives the possibility of current verification of management quality of cluster members, without waiting for periodic evaluation of ECEI award, because the quality of cluster management depends on the quality of management of cluster members. It can be a warn- ing signal before the entry of the cluster into the transition phase, as well as a tool for verifying the quality of candidates for cluster members.

\section{$2 \quad$ Literature analysis}

Reviews published online are a special type of opinion. The paper Bernatowicz and Małyszko (2014) pointed out that supporting friends in decision-making by creating a network of mutual recommendations and advice is a natural phenomenon not just among friends, but also among strangers, which partially transfers the bonding mechanisms to the Internet plane. Further reasons for consumer involvement in publishing opinions and reviews were analyzed in Bruhn, et al. (2004). It was pointed out that their purpose, besides helping, may be to harm a particular business or organization through negative reviews of its products or services that are not always truthful. It is difficult for many businesses to resist the temptation to publish manipulated reviews. For this purpose, they may resort to organized groups, which, in return for definite financial benefits, anonymously or under a changed identity, will publish unreliable information about competitors or unfounded praise of certain products or services (Liu, 2015). Some of the most common reasons for publishing reviews include the following (Directorate For Science, Technology And Innovation Committee On Consumer Policy, 2019):

- the desire to help consumers in order to avoid a bad product or recommend a good one,

- taking pleasure in sharing personal experiences (Barton, 2006), and

- the desire to put pressure on a business to elicit a specific response (Hennig-Thurau, et al., 2004) by posting negative opinions about a product or service.

There are many documented cases of success of such actions. For example, the manufacturer of Doritos crisps discontinued the use of palm oil in products sold in Poland after a series of negative comments were posted on the manufacturer's website (Mandel, 2018). Similarly, the beer producer Heineken was forced to remove its commercial from its official YouTube channel after Internet users accused it 
of racism (Taylor, 2018). Therefore, it is important to identify emotions on the basis of comments posted by Internet users.

Sentiment analysis can be of help in this regard. It is a field of research that analyzes people's opinions, feelings, evaluations, attitudes, and emotions toward entities such as products, services, organizations, people, problems, events, topics, and their attributes (Liu, 2015). It is often interchangeably referred to as overtone analysis, sentiment analysis, opinion exploration, opinion mining, sentiment exploration, subjectivity analysis, emotion analysis, etc. Although the concept of sentiment analysis first appeared in a publication recently (Nasukawa, et al., 2003), several papers on this topic had already been published before (Das, et al., 2001; Pang, et al., 2002). Because of its importance to business and society as a whole, it has influenced the development of many sciences, from computer science to management and finance (Liu, 2015).

Sentiment analysis and opinion research papers revolve around assigning the research subject to one of the classes representing positive or negative overtones (Ravi and Ravi, 2015), so that it is possible to indicate the emotional states of an opinion writer as well as to determine the emotional effect that an opinion may have (Gładysz, 2017). This can be done in different manners; the Internet users most commonly use (Małyszko, 2015):

- evaluation in the form of points or stars in the adopted scale and

- evaluation in the form of a list of advantages and disadvantages with predefined options.

In conjunction with the development of sentiment analysis and automatic Internet monitoring systems, an increasing number of studies have begun to be published that examine not only consumer product perceptions, but also health care, financial services, and social events such as presidential elections and bills enacted. For example, Liu, et al. (2007) proposed a sentiment analysis model for prediction of sales performance. One paper (McGlohon, et al., 2010) evaluated merchants through their reviews. A study on sentiment analysis of Twitter messages (Gimpe, et al., 2010) was juxtaposed with public opinion polls, while Tumasjan, et al. (2010) used Twitter to predict election results. Sentiment analysis was used by
Dzieciątko (2018) to analyze emotions in political speeches in the Sejm, and Chen, et al. (2010) investigated political views through it. In their study, Asur, et al. (2010) and Sadikov Parameswaran, and Venetis (2009) analyzed Twitter opinions on movie reviews and then predicted ticket sales revenue based on them.

Research on the use of service quality assessment and sentiment analysis was conducted in the article Chong, et al. (2016), where the sales of products were predicted based on consumer opinions. In the paper by Archak, et al. (2011), the authors analyzed consumer preferences based on online reviews. In the study by Kauffmann, et al. (2020), sentiment analysis was used to assess the quality of higher education institutions, while in the research by Młodzianowski (2018), it was used to forecast the direction of change in stock market indexes.

In this study, the analysis of online opinions of cluster and in-cluster business customers will be compared with cluster management quality as measured by the level of the ECEI label. The ECEI was established by the European Commission - the Directorate General for Enterprise and Industry. The ECEI certification system was set up to provide independent, voluntary evidence of excellence in cluster management. Its purpose is not only to discern between "good" and "bad" cluster management systems, but also to motivate managers to join and sustainably participate in the improvement process. As a first step, the process involves benchmarking against other clusters and learning from the best, and the concepts and methodologies developed are in line with continuous improvement methodologies and the European Foundation for Quality Management (EFQM) (ECEI Process, 2019). Under the ECEI certification system, one of three management quality labels is awarded. The first, lowest level is a bronze label, followed by a silver label and a gold label, which is awarded to clusters that meet all the standards defined in the ECEI Management Quality Indicators (ECEI Criteria, 2013).

In order to receive the ECEI bronze label, a cluster shall notify the European Cluster Analysis Secretariat (ESCA) of its interest in participating in the process of pursuing excellence in cluster management and then allow one of ESCA's experts to conduct bench- 
marking tests. Each cluster that received a bronze label has been reviewed based on an interview with the cluster manager conducted by an ESCA benchmarking expert (ECEI Bronze, 2019).

The ECEI silver label is already a management quality label that confirms the successful implementation of the improvement processes initiated as a result of the benchmark test of the bronze label (ECEI Criteria, 2013).

The ECEI gold label is awarded to clusters that display highly advanced management as determined by an audit conducted by an ESCA expert and are committed to further improvement of their organizational structures and procedural evolution in order to achieve even higher performance. To become a gold label awardee, cluster management organizations must meet all specified "levels of excellence" in the categories analyzed (ECEI Gold, 2019).

\section{$3 \quad$ Research procedure}

The research subject of this paper are the opinions collected on the Internet about clusters and in-cluster businesses. The study randomly selected a total of 1,200 businesses, which were represented by 14,376 opinions and 24 clusters.

For the area of inquiry thus presented, we can formulate the following main objective:

CG: Evaluation of management quality determined by analyzing the sentiment of online opinions of cluster and in-cluster business customers with the level of cluster management quality measured by the ECEI label.

The main objective will be attained through the implementation of detailed objectives:

C1: Identification and evaluation of Internet sources of opinions for the purpose of analyzing the sentiment of Internet opinions of customers of clusters and in-cluster businesses.

C2: Sentiment analysis of online opinions of customers of clusters and in-cluster businesses.

C3: Evaluation of cluster management quality measured by the ECEI label level with the results of the sentiment analysis.
In order to accomplish them, the paper focuses on answering the following research questions:

PB1. How to identify and evaluate sets of online opinion sources useful in analyzing the sentiment of clusters and in-cluster businesses?

PB2. How to estimate the sentiment level of online opinions of customers of in-cluster businesses?

PB3. Is the level of the sentiment of opinions about clusters and in-cluster businesses comparable to the quality of cluster management measured by the ECEI label level?

\section{$4 \quad$ Results}

\section{- Re. $\mathrm{C} 1$ and PB1}

Opinions posted on the Internet constitute an important factor conditioning consumer decisions. This is evidenced by studies conducted, inter alia, by BrightLocal in 2017 . They show that $97 \%$ of customers read reviews online before making a purchase and $85 \%$ of consumers trust reviews posted online (Guta, 2021). Research conducted on U.S. Internet users in 2016 found that online reviews were the most trusted source of product information in each demographic analyzed (Guttmann, 2017). A 2019 Kantar Media study surveying 5,000 respondents from Brazil, China, France, the United Kingdom, and the United States pointed to the Internet as the main source of consumer information (Kantar, 2019).

Therefore, it is of importance to adequately identify and evaluate online data sources useful in analyzing online opinion sentiment. For this purpose, "Sites Where Customers Rate You" rankings (Chaney, 2020; Dbohra, 2021; Reviewtrackers, 2021), posted on business websites, were considered. The rankings spanned from 15 to 26 websites, but only those websites that appeared in each ranking were subjected to further analysis. The next step in identifying and evaluating Internet opinion sources is to analyze them for potential use in assessing the opinion sentiment of in-cluster businesses. This analysis seeks to select those Internet opinion sources on which it is possible to find opinions about in-cluster companies.

By fulfilling the presented criteria, the most common opinion sources were identified. They are presented in Table 1. 
Table 1. Ranking of the most popular online business opinion posting sites

(Source: Own materials)

\begin{tabular}{|c|c|c|c|}
\hline \multirow{2}{*}{ No. } & \multicolumn{3}{|c|}{ Ranking } \\
\hline & smallbiztrends.com & reviewtrackers.com & dbohra.com \\
\hline 1 & $\begin{array}{l}\text { Google Maps/ } \\
\text { Google My Business }\end{array}$ & $\begin{array}{l}\text { Google Maps/ } \\
\text { Google My Business }\end{array}$ & $\begin{array}{l}\text { Google Maps/ } \\
\text { Google My Business }\end{array}$ \\
\hline 2 & Facebook & Facebook & Facebook \\
\hline 3 & OpenTable & OpenTable & OpenTable \\
\hline 4 & TripAdvisor & TripAdvisor & TripAdvisor \\
\hline 5 & Glassdoor & Glassdoor & Glassdoor \\
\hline 6 & Yelp & Vitals & FinancesOnline \\
\hline 7 & Foursquare & RateMDs & WebMD \\
\hline 8 & HomeAdvisor & Doctor.com & Manta \\
\hline 9 & Yellow Pages & get.grubhub.com & TrustRadius \\
\hline 10 & Amazon Customer Reviews & Booking.com & Bing Places \\
\hline 11 & Angie's List & Hotels.com & Better Business Reviews \\
\hline 12 & TrustRadius & Cars.com & Amazon Business Reviews \\
\hline 13 & Better Business Reviews & Yelp & Yellow Pages \\
\hline 14 & PlanetRate & SeniorAdvisor & PlanetRate \\
\hline 15 & Salesforce AppExchange & Zillow & G2 \\
\hline 16 & Trustpilot & Avvo & --- \\
\hline 17 & Bing Places & Lawyers.com & --- \\
\hline 18 & G2 & Healthgrades & --- \\
\hline 19 & VendOp & Eat24 & --- \\
\hline 20 & Manta & MenuPages & --- \\
\hline 21 & Avvo & DealerRater & --- \\
\hline 22 & WebMD & Orbitz & --- \\
\hline 23 & FinancesOnline & Travelocity & --- \\
\hline 24 & Merchant Circle & Expedia & --- \\
\hline 25 & Sitejabber & --- & --- \\
\hline 26 & Which? & --- & --- \\
\hline
\end{tabular}

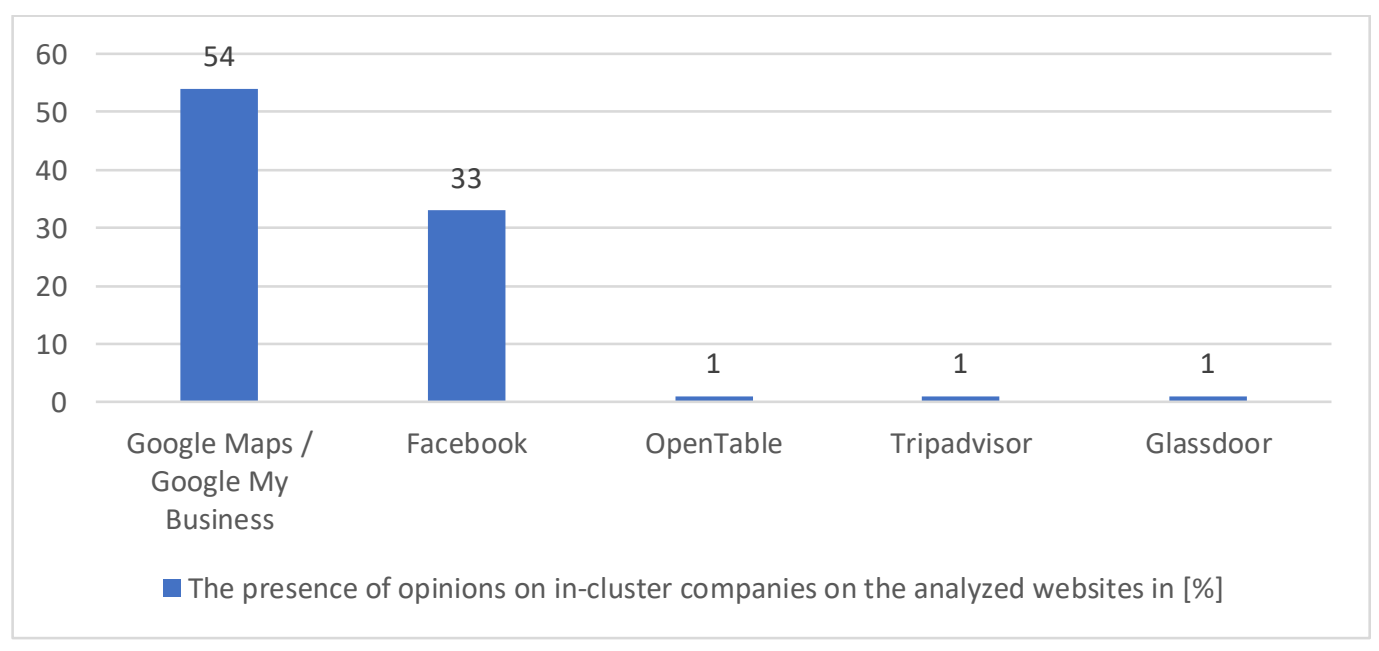

Figure 1. The presence of opinions on in-cluster companies on the analyzed websites in [\%] (Source: Own materials) 
Google Maps/Google My Business, Facebook, OpenTable, TripAdvisor, and Glassdoor were eligible for this study. The websites that appear in all three rankings are marked green in Table 1.

Another evaluation criterion was the feasibility of finding opinions about selected clusters and incluster businesses on websites qualified for further analysis. Fig. 1 presents the results of the analysis.

According to the analysis, the most common sources of opinions are Google Maps/Google My Business and Facebook, where opinions were found for 54\% and $33 \%$ of in-cluster companies, respectively. They have been identified as online sources of opinions, which will be used in the analysis of the sentiment of online opinions of cluster and in-cluster business customers.

This analysis provided an answer to the research question PB1, which in turn led to the completion of detailed objective $\mathrm{C} 1$.

OpenTable, TripAdvisor, and Glassdoor are portals that collect theme-based opinions. OpenTable features reviews of restaurants, TripAdvisor features reviews of tourism in the broadest sense, and Glassdoor features reviews of employers; therefore, they are not common and the percentage of companies from clusters on which reviews can be found on these sites is about $1 \%$.

- Re. $\mathrm{C} 2$ and PB2

The next step of the conducted research was to analyze opinion sentiment on the identified websites.
Each opinion was expressed on a 5-star scale (from $1^{*}$ to $5^{*}$ ), where 1 is the minimum value reflecting very negative sentiment and 5 is the maximum value reflecting very positive sentiment. It is also one of the most popular ways to express opinions online, as it ensures comparability of opinions between the selected online resources (Małyszko, 2015). This also allows for skipping the semantic analysis of opinions expressed in multiple foreign languages. In order to ensure reliability and avoid manipulation of posted opinions, only those companies whose number of opinions were equal to or greater than 5 were analyzed. In order to classify the analyzed clusters, the results were pinned to one of the three ECEI labels. These are gold, silver, and bronze labels. The equation below was used to estimate the sentiment level:

$$
\text { Label } Z \text { sentiment level }=\frac{\sum_{i=1}^{n} w_{z i} \bar{x}_{z i}}{\sum_{i=1}^{n} w_{z i}}
$$

where $Z$ is the label level, $i$ is the number of analyzed in-cluster businesses with $Z$ label, $w_{z i}$ is the number of opinions for the in-cluster businesses with label Z, and $\bar{x}_{z i}$ is the arithmetic mean value of opinion sentiment of the in-cluster businesses with label $\mathrm{Z}$.

However, not every in-cluster business had opinions on its subject. Moreover, in order to avoid manipulation of opinions, only those businesses for which the number of opinions was at least five were taken into account. The frequency of opinions on businesses was also analyzed. Table 2 presents the preliminary sentiment analysis results.

Table 2. Preliminary sentiment analysis results (Source: Own materials)

\begin{tabular}{|c|c|c|c|}
\hline $\begin{array}{c}\text { Number of busi- } \\
\text { nesses selected }\end{array}$ & $\begin{array}{c}\text { Number of opinions } \\
\text { analyzed }\end{array}$ & $\begin{array}{c}\text { Average sentiment level per } \\
\text { opinion (on a scale of 1-5) }\end{array}$ & $\begin{array}{c}\text { Percentage of businesses with at } \\
\text { least five reviews }\end{array}$ \\
\hline 1,200 & 14,376 & 4.299 & $57.73 \%$ \\
\hline
\end{tabular}

Among the selected companies, 691 had at least five opinions, the total number of which amounted to 14,376, and the average level of sentiment was 4.299. The analysis carried out allowed to obtain an answer to the formulated research question PB2, which enabled realization of detailed objective $\mathrm{C} 1$.

\section{- Re. C3 and PB3}

The next stage of the analysis was to assign opinions of cluster and in-cluster business customers to the appropriate level of a cluster's label. For this purpose, for each label level, the level of sentiment was estimated using the above equation.

The results are presented in Table 3. 
Table 3. Opinion sentiment level with division into label levels held by clusters (Source: Own materials)

\begin{tabular}{|l|c|c|}
\hline \multicolumn{1}{|c|}{ Cluster label } & Number of opinions surveyed & Level of sentiment (1-5) \\
\hline Gold & 5.242 & 4.447 \\
\hline Silver & 4.471 & 4.385 \\
\hline Bronze & 4.663 & 4.053 \\
\hline
\end{tabular}

In the analysis, clusters with the gold label have the highest level of sentiment, whereas clusters with the bronze label have the lowest level of sentiment.

The limitation of the obtained results stems from lack of opinions on some of the in-cluster businesses. The highest percentage of them was found in relation to the in-cluster businesses and with the gold label $66.01 \%$. Along with the decrease in management quality expressed by a cluster's label, the number of businesses having opinions also decreased. Also, $54.73 \%$ business in the silver cluster had opinions, while $51.34 \%$ of businesses in the bronze cluster had opinions. The dependence is presented in Fig. 2.

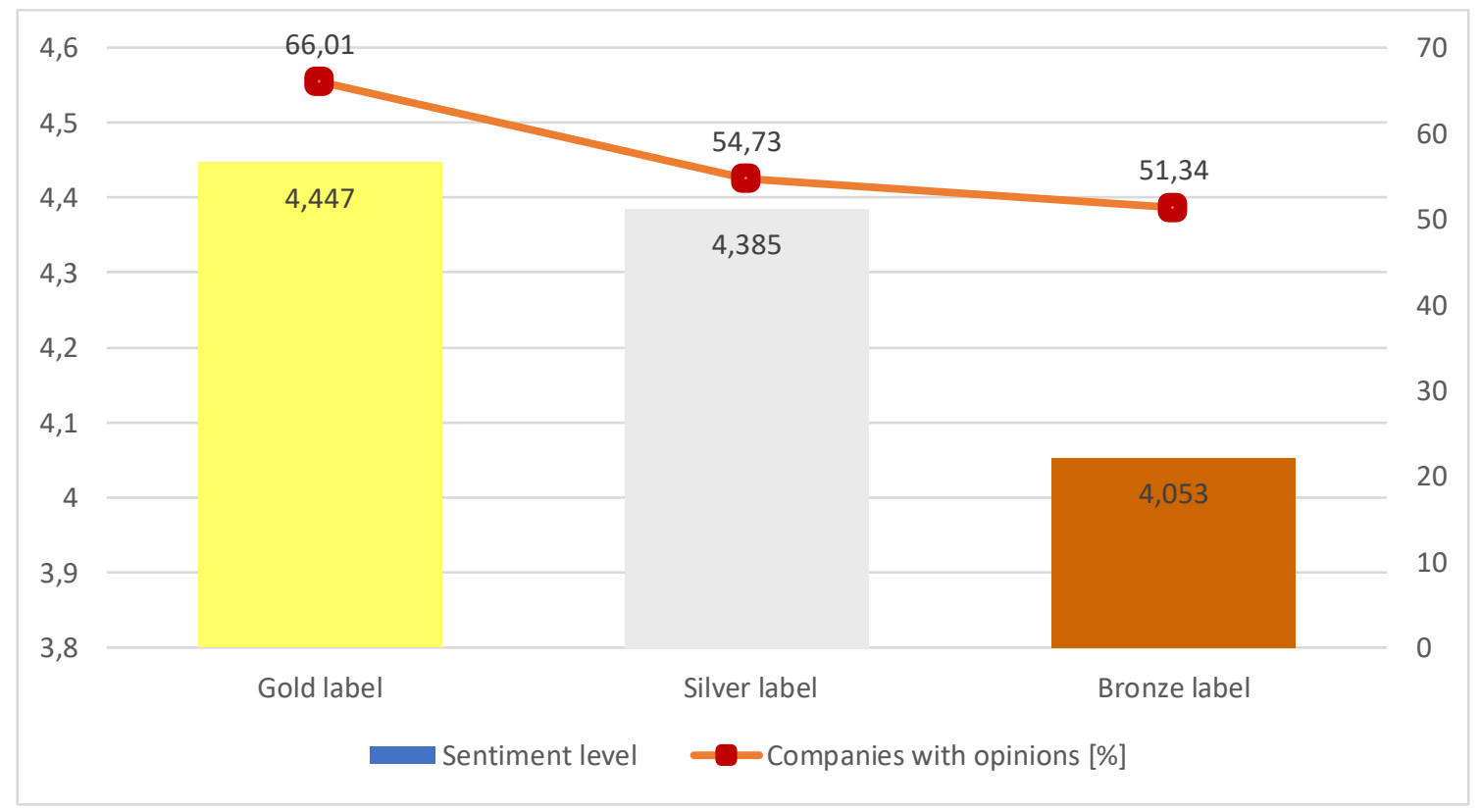

Figure 2. Dependence of label level on opinion sentiment and opinion frequency [\%]

(Source: Own materials)

On the basis of the conducted analysis, it is noticeable that the level of opinion sentiment on clusters and incluster businesses is convergent with cluster management quality measured by the ECEI label level. Along with the increase in the ECEI label level, an increase in the opinion sentiment level is seen. The highest value of opinion is attributable to the gold-labeled clusters, while the lowest value is attributable to the bronze-labeled clusters. The indicator for the level of businesses with opinions is also analogous. How- ever, in the case of businesses operating in gold-labeled clusters, $66.01 \%$ of the businesses have opinions on their own subject, whereas in the case of businesses operating in bronze-labeled clusters, this figure is only $51.34 \%$. Based on the study, a conclusion can be drawn that the opinion sentiment level toward clusters and in-cluster businesses depends on cluster management quality measured by the ECEI label level. As a result of the conducted analysis, PB3 was answered and C3 was completed. 


\section{$5 \quad$ Research results overview and discussion}

In the light of this study, there is a significant disparity between the level of customer opinion on companies and the level of label they hold. The level of sentiment for businesses operating in silver-labeled clusters was 0.332 stars higher (on a scale of $1-5$ ) than for businesses operating in bronze-labeled clusters. Noticeably, there was a lower disproportion between the level of sentiment for businesses in gold- and silver-labeled clusters. It amounted to 0.062 stars (on a scale of $1-5$ ). This may be due to the methodology of awarding the ECEI. In order to award the bronze label, it is sufficient to declare interest in participating in the process of pursuing excellence in cluster management and to allow testing by an expert. The label is awarded regardless of the result. In the case of silver and gold labels, its award is a mark of management quality, which confirms the implementation of a number of processes that improve management.

It is important to notice that there is a disproportion between the level of customer opinion on companies (cluster members) and the level of the label awarded to clusters, as this makes it possible to measure the effectiveness of the cluster's subsequent action. The ECEI evaluation system does not assume such a possibility, which hinders continuous tracking of the effectiveness of improvement actions taken by the cluster. Sentiment analysis is a complementary tool to the ECEI rating system, and ongoing monitoring of the sentiment level of customer opinions about companies (cluster members) in relation to the label level provides an opportunity to assess the effectiveness of actions taken by the cluster to improve management processes.

The cluster business opinion frequency rate is another indicator estimated in the study. There is an increase in its level as the level of the ECEI labels increases by $3.39 \%$ between the bronze and silver labels and by $11.28 \%$ between the silver and gold labels. Such a significant shift for the gold label may be related to greater recognition of in-cluster businesses with this label, longer market presence, and greater awareness of how important it is for a company to be present online.
In conclusion, the study demonstrated the relevance of the addressed issue and the presented research results allowed for completion of the defined detailed objectives and for answering the set research questions. The main objective of the paper was achieved, that is, to compare the management quality assessment based on the analysis of the Internet sentiment of customers of clusters and in-cluster businesses with the level of cluster management quality measured by the ECEI label. The hypothesis that cluster management quality positively influences the increase in customer opinion sentiment about businesses - cluster members - was also confirmed.

As a result of the above, it appears that sentiment analysis may be applied as a complementary tool in measuring the effectiveness and efficiency of various business activities reflected in the reactions of peer online communities.

\section{References}

[1] Abirami, A.M., Askarunisa, A. 2017. Sentiment analysis model to emphasize the impact of online reviews in healthcare industry. Online Information Review, 41(4), pp.471-486.

[2] Albesta, D.D., Jonathan, M.L., Jawad, M., Hardiawan, O., Suhartono, D. 2021. The impact of sentiment analysis from user on Facebook to enhanced the service quality. International Journal of Electrical \& Computer Engineering (20888708), 11(4), pp.3424-3433.

[3] Archak, N., Ghose, A., Ipeirotis, P.G., 2011. Deriving the pricing power of product features by mining consumer reviews. Management Science, 57(8), pp.1485-1509.

[4] Asur, S., Huberman, B.A., 2010. Predicting the future with social media. In 2010 IEEE/WIC/ACM International Conference on Web Intelligence and Intelligent Agent Technology, Vol. 1, IEEE., pp.492-499.

[5] Bernatowicz, A., Małyszko, J., 2014. Recenzje konsumenckie w Internecie. Społeczny kontekst publikowania opinii i analiza spójności różnych sposobów ich wyrażania (Consumer Reviews on the Internet. The Social Context of Opinion Publishing and an Analysis of the Consistency of Different ways of Expressing them), In: D. 
Appenzeller (ed.), 2014. Matematyka $i$ informatyka na ustugach ekonomii: teoria i zastosowania (Mathematics and Computer Science at the Service of Economics: Theory and Applications). Wydawnictwo Uniwersytetu Ekonomicznego w Poznaniu (Published by the University of Economics in Poznań), pp.158-168.

[6] Bruhn, M., Hennig-Thurau, T., Hadwich, K., 2004. Markenführung und Relationship Marketing. In: Handbuch Markenführung. Gabler Verlag, Wiesbaden, pp.391-420.

[7] Chaney, P., 2020. 26 Business Review Sites Where Customers Rate You. Small Business TRENDS, [online] Available at: https://smallbiztrends.com/2020/12/business-review-sites.html [Access: 08.06.2021]

[8] Chen, B., Zhu, L., Kifer, D., Lee, D., 2010. What is an Opinion About? Exploring Political Standpoints Using Opinion Scoring Model. Proceedings of the Twenty-Fourth AAAI Conference on Artificial Intelligence, pp.1007-1012. https://dl. acm.org/doi/abs/10.5555/2898607.2898768.

[9] Chong, A.Y.L., Li, B., Ngai, E.W.T., Ch'ng, E., Lee, F., 2016. Predicting online product sales via online reviews, sentiments, and promotion strategies: A big data architecture and neural network approach. International Journal of Operations \& Production Management. Vol. 36, No. 4, pp.358383. https://doi.org/10.1108/IJOPM-03-20150151

[10] Das, S., Chen, M., 2001. Yahoo! For Amazon: Extracting Market Sentiment from Stock Message Boards. In: Proceedings of the Asia Pacific Finance Association Annual Conference (APFA) Vol. 35, p.4-45.

[11] Dbohra, 2021. 15 Business Review Sites Where Customers Rate You, Branding, Business, [online] Available at: https://dbohra.com/blog/index.php/2021/01/13/15-business-review-sitescustomers-rate-you/ [Access:08.06.2021]

[12] Directorate For Science, Technology And Innovation Committee On Consumer Policy, 2018. Understanding Online Consumer Ratings And Reviews, Organisation for Economic Co-operation and Development, pp.1-25. [online] Available at: https://www.oecd.org/officialdocuments/ publicdisplaydocumentpdf/?cote $=\mathrm{DSTI} / \mathrm{CP}(20$ 18)21/FINAL\&docLanguage $=\mathrm{En} \quad$ [Access: 14.08.2021].
[13] Duan, W., Cao, Q., Yu, Y., Levy, S., 2013. Mining Online User-Generated Content: Using Sentiment Analysis Technique to Study Hotel Service Quality. In 2013 46th Hawaii International Conference on System Sciences (IEEE.), pp.31193128.

[14] Dzieciątko, M., 2018. Application of Text Analytics to Analyze Emotions in the Speeches. In International Conference on Information Technologies in Biomedicine, Springer, Cham, pp.525-536.

[15] Gimpel, K., Schneider, N., O’Connor, B., et al., 2010. Part-of-speech Tagging for Twitter: Annotation, Features, and Experiments. CarnegieMellon Univ Pittsburgh Pa School of Computer Science.

[16] Gładysz, A., 2017. Analiza wydźwięku polskojęzycznych opinii konsumenckich: implementacja algorytmu tworzenia słownika wydźwięku. Overtone Analysis of Polish-language Consumer Opinions: Implementation of an Algorithm for Creating an Overtone Dictionary). Autobusy: technika, eksploatacja, systemy transportowe (Buses: technique, operation, transport systems), Vol. 12, p.1692-1697.

[17] Guta, M., 2017. 97\% of Customers Read Online Reviews, Survey Says. Small Business Trends. [online] Available at: https://smallbiztrends.com/2017/11/2017-local-consumer-review-survey.html [Access: 02.08.2021]

[18] Guttmann, A., 2017. Most Trusted Sources for Product Information in the U.S. in 2016, Advertising \& Marketing, [online] Available at: https://www.statista.com/statistics/251456/content-online-shoppers-trust-when-researchingproducts-in-the-us/ [Access 05.08.2021]

[19] Jeyapriya, A., Selvi, C.K., 2015. Extracting Aspects and Mining Opinions in Product Reviews Using Supervised Learning Algorithm. Proceedings of the 2nd International Conference on Electronics and Communication Systems (ICECS), IEEE, pp.548-552.

[20] Kantar Media, 2019. What Brand Information Sources Do People Trust the Most?. MarketingCharts. [online] Available at: https://www. marketingcharts.com/brand-related-108281 [Access 05.08.2021].

[21] Kauffmann, E., Peral, J., Gil, D., Ferrández, A., Sellers, R., Mora, H. 2020. A Framework for Big 
Data Analytics in Commercial Social Networks: A Case Study on Sentiment Analysis and Fake Review Detection for Marketing Decision-Making. Industrial Marketing Management, 90, pp.523-537.

[22] Liu, B. 2011. Opinion Mining and Sentiment Analysis. In: B. Liu (ed.), 2011. Web Data Mining. Springer, Berlin, Heidelberg, pp.459-526.

[23] Liu, B., 2015. Sentiment Analysis, Cambridge University Press, pp.259-301.

[24] Liu, Y., Huang, X., An, A., Yu, X. 2007. ARSA: A Sentiment-aware Model for Predicting Sales Performance Using Blogs. Proceedings of the 30th Annual International ACM SIGIR Conference on Research and Development in Information Retrieval, pp. 607-614.

[25] Małyszko, J., 2015. Automatyczne przetwarzanie recenzji konsumenckich dla oceny użyteczności produktówi ustug (Automatic Processing of Consumer Reviews for Usability Evaluation of Products and Services). Rozprawa doktorska ( $\mathrm{PhD}$ thesis), doctoral supervisor: Abramowicz, W., Poznań University of Economics and Business, p. 16-155.

[26] Mandel, A., 2018. Producent Doritos ujawnia olej palmowy zniknie ze składu przekąsek (Doritos Manufacturer Reveals - Palm Oil Will Disappear from Snack Ingredients), Rzeczpospolita, [online] Available at: https://www.rp.pl/Przemysl-spozywczy/180909587-Producent-Doritosujawnia--olej-palmowy-zniknie-ze-skladu-przekasek.html [Access: 14.10.2018].

[27] McGlohon, M., Glance, N., Reiter, Z., 2010. Star Quality: Aggregating Reviews to Rank Products and Merchants. Proceedings of Fourth international AAAI Conference on Weblogs and Social Media, pp.114-121.

[28] Młodzianowski, P., 2018. A Study of the Influence of Online Information on the Changes in the Warsaw Stock Exchange Indexes. Acta Universitatis Lodziensis, Vol. 335, No 3, pp.123-138.

[29] Nakayama, M., Wan, Y., 2019. The Cultural Impact on Social commerce: A Sentiment Analysis on Yelp Ethnic Restaurant Reviews. Information \& Management, 56(2), pp. 271-279.

[30] Nasukawa, T., Yi, J., 2003. Sentiment Analysis: Capturing Favorability Using Natural Language
Processing. In Proceedings of the 2nd international conference on Knowledge capture, pp. 7077.

[31] Pang, B., Lee, L., Vaithyanathan, S., 2002. Thumbs up? Sentiment classification using machine learning techniques. arXiv:cs/0205070.

[32] Perkins, B., Fenech, C., 2016. The Deloitte Consumer Review The Growing Power of Consumers, A Deloitte Insight report, [online] Available at: https://www2.deloitte.com/content/dam/Delo itte/uk/Documents/consumer-business/consumer -review-8-the-growing-power-of-consumers.pdf [Access: 11.08.2021]

[33] Pozzi, F. A., Fersini, E., Messina, E., Liu, B., 2016. Sentiment Analysis in Social Networks. Morgan Kaufmann, p.18-21.

[34] Ravi, K., Ravi, V., 2015. A Survey on Opinion Mining and Sentiment Analysis: Tasks, Approaches and Applications. Knowledge based systems, 89, pp.14-46.

[35] Reviewtrackers, 2021. 19 Business Review Sites for Improving Your Brand Visibility. Reviewtrackers, [online] Available at: https://www.reviewtrackers.com/guides/business-review-sites/ [Access: 08.06.2021]

[36] Sadikov, E., Parameswaran, A., Venetis, P. 2009. Blogs as predictors of movie success. In Proceedings of the International AAAI Conference on Web and Social Media, Vol. 3, No. 1.

[37] Taylor, K., 2018. Reklama piwa Heineken wycofana. Po oskarżeniach o rasizm (Heineken Beer ad Withdrawn. After Accusations of Racism), BUSINESS INSIDER, [online] Available at: https://businessinsider.com.pl/media/reklama/hei neken-wycofal-reklame-po-oskrazeniach-o-rasiz m/3816prn [Access: 14.10.2018]

[38] Tumasjan, A., Sprenger, T., Sandner, P., Welpe, I., 2010. Predicting Elections with Twitter: What 140 Characters Reveal about Political Sentiment. In Proceedings of the International AAAI Conference on Web and Social Media, Vol. 4, No. 1.

[39] Qazi, A., Tamjidyamcholo, A., Raj, R.G., Hardaker, G., Standing, C., 2017. Assessing Consumers' Satisfaction and Expectations through Online Opinions: Expectation and Disconfirmation Approach. Computers in Human Behavior, 75 , pp.450-460. 